\title{
ESTRUTURA DE UMA AULA TEÓRICA I: CONTEÚDO
}

\author{
STRUCTURE OF A LECTURE I: CONTENT
}

Antonio Pazin Filho ${ }^{1}$, Sandro Scarpelini ${ }^{2}$

Docentes. 'Departamento de Clínica Médica. ${ }^{2}$ Departamento de Anatomia e Cirurgia. Faculdade de Medicina de Ribeirão Preto - USP. Correspondência: Antonio Pazin Filho. Centro de Estudos de Emergências em Saúde - CEES.

Rua Bernardino de Campos, 1000 - 14015-030 - Ribeirão Preto - SP. apazin@fmrp.usp.br

Pazin Filho A, Scarpelini S. Estrutura de uma aula teórica I: Conteúdo. Medicina (Ribeirão Preto) 2007; 40 (1): 17-27.

RESUMO: Durante o processo de elaboração do conteúdo de uma aula teórica, o palestrante deve selecionar e integrar as noções que deseja transmitir, considerando a capacidade de retenção da platéia. O primeiro passo deve ser a definição de objetivos, ou seja, o que se pretende que seja retido ao final da aula. A partir deste conhecimento, o palestrante deverá selecionar pequenas parcelas de informação (tópicos) que embasam o que se quer transmitir, utilizando também ilustrações (evidências). Estes tópicos/evidências devem ser coesos, garantindo uma estrutura de começo-meio-fim para a aula. É fundamental levar em consideração nesta elaboração a capacidade de retenção da platéia, influenciada pela forma como é transmitida a informação, a quantidade de conhecimento transmitido, a duração da atividade e as intervenções que o palestrante pode fazer. Todas estas características fundamentam que o conteúdo deve ser cuidadosamente selecionado, transmitindo-se pouco informação de forma a garantir a retenção.

Descritores: Aula Teórica; conteúdo; elaboração; retenção. Educação Médica.

Você só consegue explicar aquilo que entendeu. Joelmir Betting

\section{1- INTRODUÇÃO}

A primeira fase de elaboração de uma aula teórica diz respeito ao conteúdo que se quer transmitir. Alguns princípios devem ser respeitados ao se selecionar este conteúdo, o que se constitui no objetivo deste artigo.

Basicamente, lidamos com o conteúdo em dois planos distintos: o primeiro representado por toda a elaboração interna que o palestrante tem que realizar previamente e o segundo está relacionado à capacidade da platéia em reter o conteúdo que está sendo transmitido.

\section{2- ELABORAÇÃO INTERNA DO CONTEÚDO}

Um primeiro ponto filosófico que deve ser apresentado é que a aula teórica é uma atividade elaborada por um palestrante que deve ter conhecimento na área. Ela não é somente a transmissão de conhecimento, mas sim a transmissão de conhecimento na interpretação de alguém. Considerar este conceito é muito importante por quatro motivos.

Em primeiro lugar, o fato de ser algo manufaturado, interpretado, é uma das maiores vantagens da aula teórica. Quando bem elaborada, ela permite não só que o aluno tenha uma visão do conteúdo que está sendo transmitido, mas de como o palestrante pensa, pondera o assunto. Quando estamos envolvidos numa aula teórica, permitimos que a platéia entre no nosso 
raciocínio, ensinando aos nossos expectadores aquilo que valorizamos no conhecimento. A simples transmissão de conhecimento, desprovida de interpretação, é melhor conseguida por estudos isolados diretamente em livros ou artigos, que mesmo assim carecem de isenção na grande maioria dos casos.

Um segundo ponto a ser ressaltado é que para se elaborar e interpretar algo, precisamos integrar o conhecimento internamente. Alguns acreditam que ao se aprender as técnicas de didática necessárias, poderão dar qualquer aula sobre qualquer assunto. Isto não é verdade, pois para que possamos ensinar alguma coisa, temos que ter aprendido primeiro. "Você só aprende alguma coisa quando vê uma vez, faz uma vez e ensina uma vez". Para ensinar, precisamos compreender o assunto, internalizá-lo, integrá-lo dentro da nossa visão de mundo e nos tornarmos confortáveis a ponto de expressá-lo para outras pessoas. Não há técnica que possibilite este tipo de atividade, o que torna uma aula teórica dada por um especialista na área algo tão precioso. Não deve ser depreendido, no entanto, que as técnicas não são importantes. Todo o conhecimento do especialista é perdido, se ele não souber como transmití-lo. Os dois objetivos devem ser perseguidos.

O terceiro motivo é que esta elaboração interna é um dos motivos que torna a aula teórica como uma impressão digital do palestrante. Por mais que se tente copiar uma aula teórica bem sucedida, isto não será possível, pois teríamos que mimetizar todo o jeito de pensar da pessoa que elaborou a aula. Cada pessoa deve desenvolver o seu próprio método de aula, utilizando os recursos descritos neste simpósio e outras fontes como auxiliares neste desenvolvimento.

Por fim, é importante para o aluno ter a consciência de que a aula teórica é uma interpretação. A aula deve ser vista como algo que orienta, que auxilia no estudo, que fornece subsídios para uma elaboração própria, mas não como verdade universal. Ela é por definição a visão de quem a elaborou, sendo de maior valor na dependência do grau de elaboração desta pessoa, mas também por definição, incluindo todas as limitações desta pessoa sobre o assunto. Nenhuma aula substitui o estudo através de outras fontes, pois nossa interpretação de um fato é muito melhor quando temos diversas pontos de vista sobre o mesmo assunto.

O processo de elaboração de uma aula é baseado na nossa capacidade de interpretação e integração. É um processo solitário, interno, que exige livre associação dos fatos absorvidos e que culmina na ordenação do conteúdo para transmissão de uma men- sagem com o intuito de convencer a platéia de nossa visão dos fatos. Ou seja, a elaboração da aula nada mais é que a construção de um argumento, baseado numa série de fatos e ilustrações pelos quais se pretende convencer as pessoas do conhecimento a ser transmitido. Argumento está sendo utilizado aqui no sentido mais puro da palavra e nada tem a ver com contentas. Argumento é um instrumento pelo qual se objetiva convencer as pessoas através da razão e para que seja considerado eficaz ele deve assumir a estrutura de começo-meio-fim, ou seja, ele parte de uma premissa, fornece fatos e propõe uma conclusão. Um outro ponto interessante sobre esta mensagem a ser transmitida é que ela tem a pretensão de convencer os expectadores do que se quer transmitir, mas deve fazer isto de modo natural, sem forçar este ponto de vista.

A primeira etapa a ser cumprida na elaboração da aula é, portanto, definir qual a mensagem que se quer transmitir. Estes são nossos objetivos, ou seja, o que se espera que seja retido ao final da aula. Qual é a mensagem que o aluno irá efetivamente reter? Geralmente não se faz distinção entre objetivo e mensagem, mas aqui estes termos são diferenciados para motivos de elaboração do raciocínio. Entenda-se objetivo como o que se pretende passar e mensagem como o que foi efetivamente transmitido.

A Figura 1 ilustra a disposição do objetivo a ser transmitido e a da mensagem que efetivamente se conseguiu transmitir de modo abstrato (situação A) e num exemplo concreto (situação B). Para se cumprir este objetivo, desenvolveremos todo um raciocínio, uma argumentação, que geralmente é baseada em tópicos a serem discutidos e evidências que validam estes tópicos. Entendam-se tópicos e evidências como ferramentas que nos permitirão elaborar o argumento para nossos ouvintes.

Um tópico é um ponto que deve ser apresentado por ser fundamental para a compreensão da mensagem ou por ser um ponto que restrinja a aceitação do que se quer transmitir. Na Situação B da Figura 1, expõe-se um exemplo concreto de uma aula sobre tratamento não-intervencionista do infarto agudo do miocárdio. Para se transmitir a mensagem das formas de tratamento e fatores que as influenciam, podemos discutir vários tópicos. Um primeiro tópico (1 na Situação $\mathrm{B}$ da Figura 1) diz respeito à patogênese do trombo no infarto agudo, que é um exemplo de uma informação que embasa todo o conceito que se quer transmitir. Nosso objetivo não é transmitir a gênese do infarto agudo do miocárdio, mas sem esta informação 


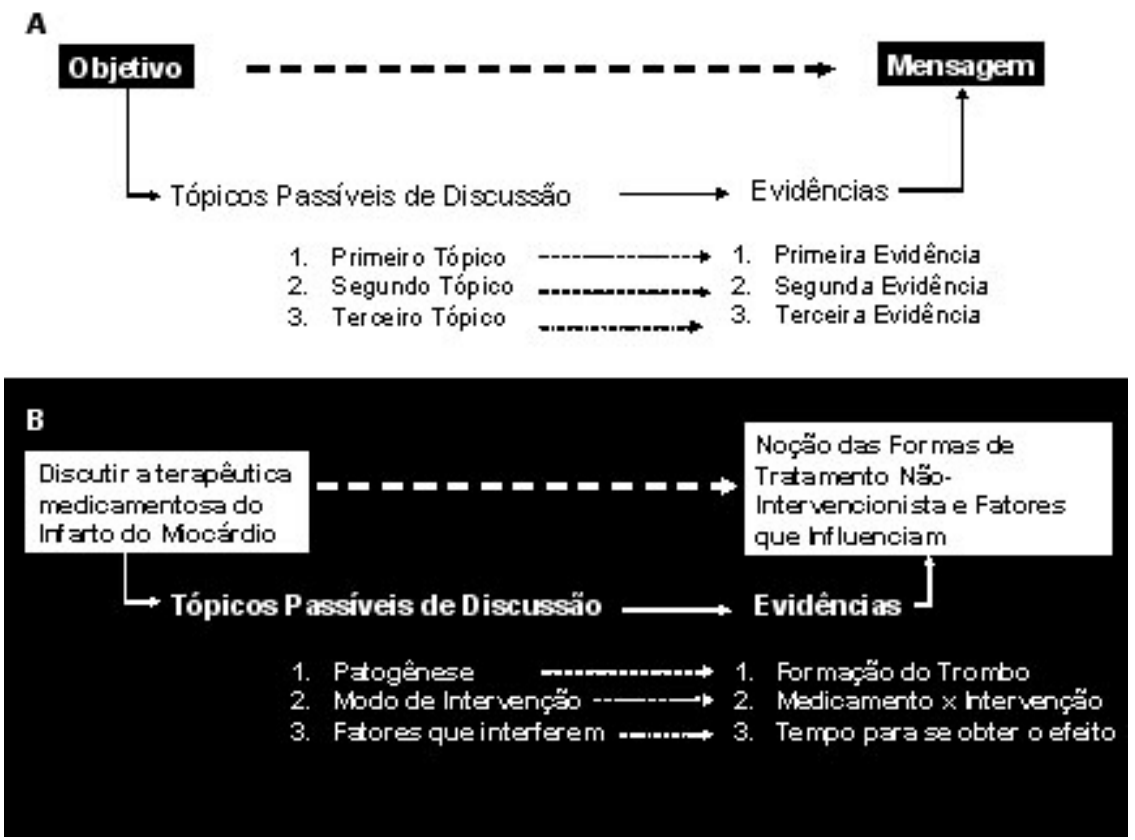

Figura 1: Objetivo e Mensagem.

A - Inter-relação entre Objetivo (o que se pretende transmitir) e Mensagem (o que efetivamente foi transmitido) no plano teórico. A transmissão do conteúdo é realizada através da identificação de tópicos (conceitos a serem transmitidos) e apresentação de evidências (ilustração dos conceitos). Por melhor elaborado que seja este método, ele se constitui num filtro que modifica a Mensagem quando se comparada ao que se tinha como Objetivo.

B - Exemplo da inter-relação entre Objetivo e Mensagem. Utiliza-se a terapêutica medicamentosa do infarto agudo do miocárdio para ilustrar os conceitos teóricos expostos em A.

pode ser difícil ou impossível discutir tratamento. Um outro tópico (2 na Situação B da Figura 1) exemplifica uma condição que pode limitar a aceitação da nossa mensagem. Ao se discutir a terapêutica não-intervencionista, uma pergunta freqüente na linha de raciocínio de quem assiste será o que é o tratamento intervencionista. Não é nosso objetivo discutir este tipo de tratamento, mas apresentá-lo de modo sucinto mantém a atenção da platéia na nossa linha de raciocínio.

Tópicos não são estruturas fixas, mas é muito comum que sejam recorrentes em diversas formas de apresentação. Assim, por exemplo, ao assistirmos uma aula sobre tratamento, é comum que encontremos a sequiência de fisiopatologia, ação farmacológica, fatores que influenciam esta ação e posologia. Isto se dá pois é a sequiência natural de um argumento para transmissão deste tipo de informação. Do mesmo modo, ao lidarmos com uma doença infecto-contagiosa, alguns dos tópicos a serem incluídos são a biologia do agente, condições de transmissão, etc. Isto nos ajuda a elaborar a aula, mas não é necessário que a aula deva necessariamente conter todos estes tópicos. Eles podem e devem ser individualizados dependendo de quem ela- bora a aula, pois podemos entregar a mesma mensagem de diversos modos. Outro ponto fundamental sobre tópicos é que eles não são nossos objetivos. É muito comum confundí-los com objetivos, principalmente porque a forma da aula é muito baseada nestes tópicos e nas evidências apresentadas (vide capítulo sobre Forma).

A Figura 2 ilustra o processo de seleção dos tópicos. O primeiro passo é identificar as áreas de conhecimento (assinaladas I, II e III na etapa A da Figura 2) que serão abordadas. Estas áreas podem ser campos distintos, como anatomia, fisiologia e farmacologia, por exemplo, ou sub-áreas dentro de um mesmo campo de atuação.

A próxima etapa é identificar dentro de cada uma destas áreas qual é a quantidade de informação que será necessária para nossos objetivos (etapa B da Figura 2). Esta é uma fase muito delicada e que deve levar em consideração a clareza do que pretendemos transmitir e a capacidade de retenção da nossa platéia. No nosso exemplo na Situação B da Figura 1 será necessário resgatar a anatomia normal de uma artéria coronária. Não teremos condições, e nem é o 
nosso objetivo, revisar toda a anatomia da circulação coronariana, mas teremos que identificar a mínima porção necessária. Temos que limitar a quantidade de informação transmitida e, na medida do possível, simplificar ao máximo, facilitando a compreensão. Não significa dizer que queiramos ser simplistas. Se ao elaborarmos a aula, determinamos que o conteúdo que deve ser transmitido não pode ser simplificado e ocupará uma grande extensão da atividade, temos que remodelar nossos objetivos e adequá-los, dividindo o assunto em duas ou mais aulas, por exemplo. Devese salientar, no entanto, que este é um dos pontos em que mais falhamos ao elaborar a aula, pois muitas vezes fugimos do objetivo pela nossa atração por determinado ponto. Lembre-se sempre que a aula tem o objetivo de transmissão de uma mensagem específica para a platéia e não de mostrar erudição ou profundidade de conhecimento. Isto pode implicar que tenhamos que sacrificar alguns pontos do conhecimento que nos são mais atrativos.

Uma vez identificados cada um dos pontos necessários, eles devem ser isolados do restante (etapa $\mathrm{C}$ da Figura 2) e ordenados de forma que possamos construir os conceitos a serem transmitidos (etapa D da Figura 2). A etapa final (etapa E da Figura 2) é dada não só pela ordenação, mas pela concatenação do conteúdo de forma que ele tenha um sentido maior do que suas partes isoladas. Elas estarão firmemente consolidadas numa estrutura de começo-meio-fim, integradas de forma que seja tão lógica a sua continuidade que não tenhamos problemas em "contar" a história. Este ponto de integração é tão importante que serve como parâmetro se escolhemos os tópicos de modo adequado ou não. Se não for possível integrar as informações que selecionamos, devemos excluir a informação díspare ou acrescentar a informação necessária para que haja coesão.

Uma vez selecionados os tópicos, vamos determinar as evidências que serão apresentadas para justificá-los. Podemos pensar nas evidências como sendo a ilustração do conceito traduzido pelo tópico. Voltando ao exemplo da patogênese do infarto agudo do miocárdio (item 1 da Situação B na Figura 1), definimos que neste tópico será importante expor o conceito de trombo sobre placa. O modo como exporemos este conceito é o que se considera a evidência, que pode ser de diversas naturezas. Não se deve confundir as evidências que justificam os tópicos como fruto de trabalho científicos. Estamos discutindo evidência como recursos de construção de um argumento e elas
A

।

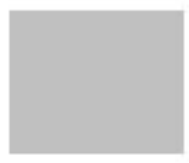

$\mathrm{B}$

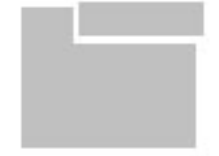

II
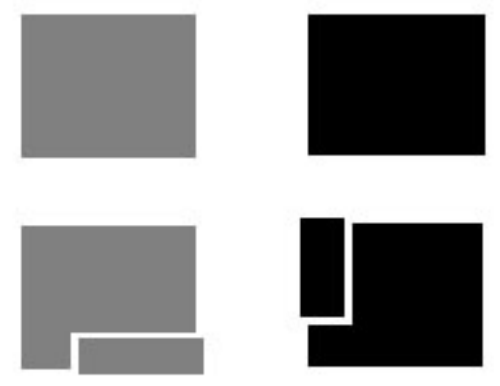

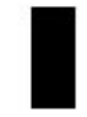

III

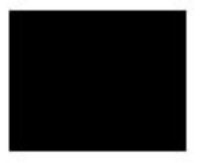

I

D

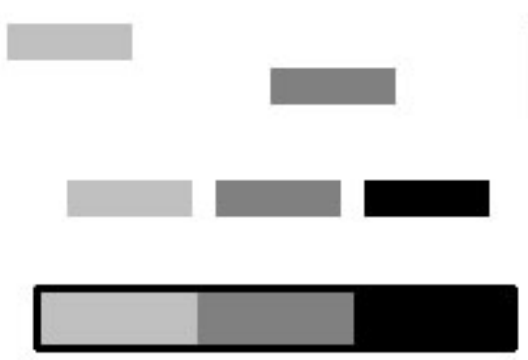

Figura 2: Construção de Tópicos

A - Seleção das áreas de conhecimento que deverão ser utilizadas para transmissão do conhecimento.

B - Delimitação da porção de conhecimento que será necessária

C - Isolamento da porção do conhecimento delimitada

D - Ordenação das diversas porções

E - Concatenação das diversas porções para se ter uma estrutura de começo-meio-fim (tópico) 
podem variar desde um esquema didático (figura) até a exposição de um trabalho científico. É lógico que as evidências apresentadas em aulas teóricas em ambiente universitário geralmente utilizam trabalhos científicos como base do conhecimento, mas isto não é necessário para a transmissão do conhecimento. Voltando ao exemplo, podemos expor a patogênese expondo figuras esquemáticas de uma artéria coronária com formação do trombo. Também podemos expor os dados quantitativos de um dos trabalhos de anatomia patológica que deu origem ao conhecimento de formação de trombo. São dois métodos distintos (evidências) para o mesmo tópico. Como as evidências estão muito correlacionadas com a forma da aula, elas serão melhor discutidas neste capítulo. Do ponto de vista do conteúdo, no entanto, cabe dizer que também é comum que alguns tipos de evidência estejam muito relacionadas a alguns assuntos específicos. No exemplo da fisiopatogênese, geralmente se apresenta o conceito através de uma figura ou várias figuras mostrando as diversas fases da formação do trombo.

A relação entre tópicos e evidências é muito importante. Não há regra sobre o número de evidências que devem ser apresentadas para cada tópico, mas por restrições de tempo geralmente restringe-se o número para uma ou duas evidências. É fundamental que a evidência apresentada justifique ou ilustre o tópico. Embora pareça lógico, é comum o erro de que não exista associação ou esta associação deixe margem para dúvidas. Caso isto aconteça, o aluno não conseguirá prosseguir para o próximo tópico, em virtude da necessidade de concatenação com o conteúdo apresentado. Além disso, cada bloco tópicoevidência(s) deve estar conectado com o próximo tópico. Todos os blocos devem dar um sentido de começo-meio-fim para a aula.

Não é necessário que sejamos limitados a um único objetivo. Na verdade, geralmente procuramos passar um número maior de mensagems a cada aula e a maior limitação para isto será a capacidade de retenção da platéia. Ao aumentarmos o número de objetivos, a relação entre tópicos e objetivos se torna mais complexa e merece ser detalhada. A Figura 3 ilustra a elaboração de uma aula com dois objetivos (I e II). Para cada um dos objetivos, determinamos que teremos que abordar três tópicos e suas respectivas evidências através do método descrito na Figura 2, que estão ilustrados para cada um dos objetivos (I - 1, 2 e 3; II - A, B e C). Observe que alguns tópicos são comuns a ambos os objetivos (I1 e IIA; I3 e IIC), o
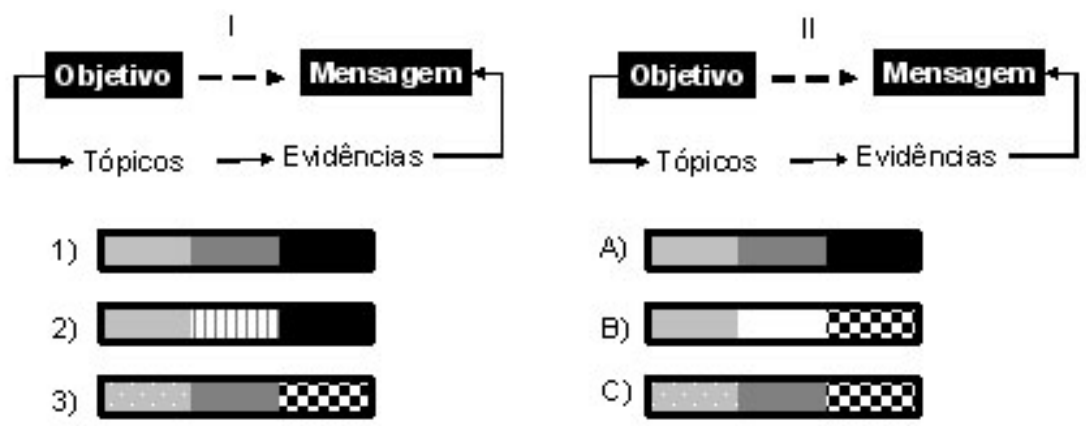

A)
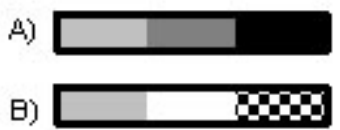

3)
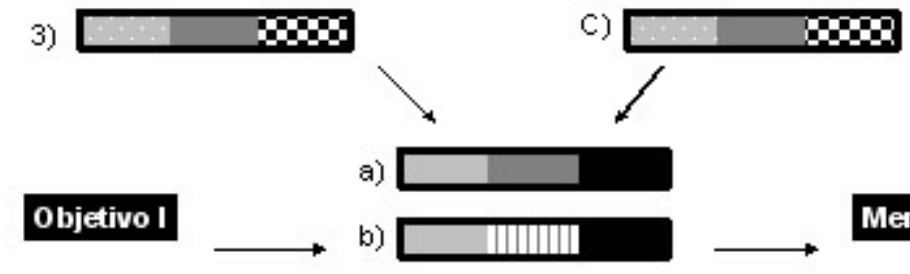

a)

b)

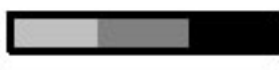

Objetivo II

c)

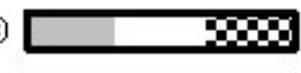

Mensagem I

d)

Figura 3: Integração entre Objetivos e Tópicos

São expostos dois objetivos inter-relacionados (I e II) que serão apresentados numa aula teórica. Para a elaboração destes objetivos, utiliza-se a construção de argumentos, baseados em tópicos e evidências, como anteriormente ilustrado nas Figuras 1 e 2 . Como os objetivos são inter-relacionados, alguns dos tópicos selecionados são coincidentes e para se evitar repetição desnecessária, ordenase os tópicos numa ordem crescente de complexidade. Isto faz com que os tópicos tenham uma estrutura linear, que na maioria das vezes não é necessária para a transmissão dos objetivos. 
que é de se esperar, pois numa aula sobre um tema específico é de se esperar que os objetivos estejam interconectados. Na composição da aula, poderíamos primeiro apresentar o objetivo I, com seus três tópicos e, posteriormente, o objetivo II com seus três tópicos. No entanto, como algumas informações são comuns aos dois objetivos, o método mais empregado é o exemplificado na porção inferior da Figura 3, na qual se observa que listamos os diversos tópicos $(\mathrm{a}-\mathrm{d})$ pelos quais pretendemos apresentar os dois objetivos. Com isto ganhamos tempo. O problema com este tipo de aproximação é que ele aumenta ainda mais a confusão entre tópicos e objetivos. Não é um fator limitante, mas requer do palestrante o conceito claro do que ele quer transmitir.

O resumo dos conceitos transmitidos está ilustrado na Tabela I.

\section{3- RETENÇÃO DO CONHECIMENTO}

A capacidade de retenção do conteúdo é um fator muito importante a ser levado em consideração tanto na elaboração como no decorrer da aula teórica. Nossa capacidade de retenção é influenciada por uma série de fatores, com destaque para a forma como adquirimos esta informação, a quantidade de informação transmitida, a duração da exposição e as intervenções que este processo pode sofrer.

A absorção do conhecimento é dada por vários níveis de comunicação verbal e não-verbal. Quanto maior a quantidade de canais utilizados para se absorver esta informação, maior será a proporção de retenção. Para se ilustrar o que se expôs, somos capazes de reter $10 \%$ do que lemos, $20 \%$ do que ouvimos, $30 \%$ do que vemos, $50 \%$ do que vemos e ouvimos e $80 \%$ do que vemos, ouvimos e fazemos. Pelo exposto, quanto maior o nosso envolvimento com a atividade, maior será a sua retenção, o que é um excelente princípio a ser considerado na elaboração de atividades didáticas. Podemos aumentar a retenção do conhecimento utilizando maior envolvimento, como por exemplo, ao invés de simplesmente oferecer o conceito em um diapositivo, podemos distribuir folhas de papel que contenham pedaços incompletos de informação que o aluno deverá preencher durante o desenvolvimento da atividade. Ao invés de apenas ver e escutar o conceito, ele terá agora que escrever o conceito ao mesmo tempo, o que amplia a retenção.

A quantidade de informação a ser transmitida é um fator limitante importante. Nossa retenção é in-

\section{Tabela I - Elaboração Interna do Conteúdo}

\section{Aula teórica como interpretação}

a. Vantagem - permite acompanhar o raciocínio de um especialista

b. Desvantagem - quando utilizada como única fonte de estudo fornece uma visão potencialmente limitada do conteúdo por se tratar de uma interpretação

\section{Aula teórica como argumento}

a. Objetivos - o que se pretende que o aluno deve reter; deve ser determinado previamente e explicitado durante a atividade. Requer ênfase durante a aula para aumentar a retenção.

b. Tópicos - porções de informação que favorecem a construção do argumento; construídos através de identificação, isolamento, ordenação e concatenação da informação necessária.

c. Evidências - ilustração do conceito transmitido pelos tópicos; adquirem várias formas de acordo com o tipo de informação transmitida.

d. Concatenação Tópico/Evidência - os exemplos (evidências) devem justificar as asserções (tópicos).

e. Concatenação inter-Tópicos - a aula tem que ter começo-meio-fim, o que requer que os tópicos estejam interconectados.

versamente proporcional à quantidade de informação transmitida. O corolário disto é que devemos limitar a quantidade de informação a ser transmitida numa aula teórica. Este é talvez o conceito mais difícil de se adquirir ao estudarmos didática. Quando desenvolvemos uma aula, queremos transmitir a maior quantidade de conhecimento possível para nossos alunos, o que é um erro, pois isto não será retido. Ao invés, devemos utilizar este tempo para passar poucas informações, mas de modo repetitivo e com o maior grau de ilustração e exemplos possíveis, pois isto ampliará a retenção. Uma aula não pode cobrir todo o conteúdo a ser discutido num curso. Outras atividades didáticas são mais efetivas para cumprir outros objetivos e a diversificação entre estas atividades é a melhor maneira de se cumprir estes objetivos.

A retenção é fortemente influenciada pela duração da exposição. De um modo geral, quanto maior 
a duração da atividade, menor será a retenção. Alguns acreditam que são preferíveis aulas de maior duração, para se ter maior oportunidade de se discutir o que se pretende com calma. O problema com esta crença é que ela não leva em consideração a capacidade de retenção das pessoas expostas à atividade.

Um princípio ainda mais importante que o impacto geral da duração da atividade na retenção é o fato de que a retenção não é uniforme ao longo da exposição. A Figura 4 ilustra três situações possíveis sobre este tópico que nos permitirão ilustrar os conceitos a serem discutidos. Todos os cenários da Figura 4 levam em consideração condições ideais de transmissão de conhecimento, como preparo do ambiente e elaboração interna da aula. As variáveis que iremos explorar serão a duração e as intervenções de diversas naturezas que o palestrante pode fazer.

A Situação A da Figura 4 ilustra a variação da porcentagem de retenção em função do tempo numa aula de 60 minutos de duração. Um primeiro ponto importante a se observar é que a maior retenção obtida não ultrapassa $50 \%$ do conteúdo que está sendo transmitido e se dá nos primeiros 10 a 15 minutos da aula, assinalados com um asterisco (*) na Figura 4. Um segundo ponto de retenção mais exacerbada, embora de menor intensidade ocorre no final da aula, assinalado com o símbolo \# na Figura 4. Estes conceitos são naturalmente observados durante uma aula teórica. Como expectadores, geralmente nos focamos no que está sendo dito no ínicio da aula para ver se nos interessa e qual serão os objetivos a serem adquiridos. No transcorrer da aula, nossa atenção é gradativamente desviada por outros estímulos, como no exemplo das conversas paralelas no capítulo sobre Aprendizado do Adulto. Quando nos damos conta que a atividade está para ser encerrada, voltamos nossa atenção novamente para o palestrante, numa tentativa de resgatar o que não conseguimos reter previamente. Esta observação de que a retenção é flutuante, com pontos estabelecidos de maior intensidade é muito importante a ser considerada na elaboração da aula. São nestes momentos que devemos concentrar as informações mais importantes que queremos transmitir. Um método de se obter isto é definir quais são os objetivos que se quer transmitir na aula, ordená-los de acordo com a sua importância e transmitir os conceitos mais importantes nos momentos de maior retenção.

Um modo de se tentar uniformizar a retenção é o exposto na situação B da Figura 4. Ele se constitui simplesmente na diminuição do tempo da aula, con- centrando-se a informação a ser transmitida. Observe que em menor tempo de aula, a média e mediana da retenção são maiores do que os da Situação A. Ao limitarmos o tempo de exposição, deletamos principalmente o período do "meio" da aula da Situação A em que ocorre maior dispersão dos expectadores.

A Situação C da Figura 4 ilustra outras formas de ampliar a retenção. Nesta situação, mantemos a duração da aula em 60 minutos como na Situação A, mas nos concentramos nos pontos nos quais prevemos que haverá diminuição da retenção e programamos intervenções para maximizar a retenção (ilustradas pelas setas na Situação C da Figura 2). Observe que a primeira seta, a que está preenchida totalmente, ilustra uma intervenção no momento de menor retenção da aula e que logo após esta intervenção temos um aumento da retenção. A segunda seta, não preenchida, que se segue à primeira, também ocorre num momento em que a retenção diminui, mas seu efeito em aumentar a capacidade de retenção é menor que a primeira intervenção. Isto ilustra a limitação que as intervenções, por melhores que sejam, terão na ampliação da retenção. Uma intervenção bem posicionada é muito boa, mas a platéia vai se tornando refratária a estas intervenções. Observe também que, mesmo com intervenções para ampliar a retenção, a média e a mediana da Situação C, embora superiores às da Situação $\mathrm{A}$, ainda são inferiores às da Situação $\mathrm{B}$, em que simplesmente atuamos sobre a duração da aula.

Intervenções são o quarto ponto a influenciar nossa capacidade de retenção e podem ser de natureza diversa. Um primeiro exemplo de intervenção é a repetição dos conceitos a serem transmitidos ao longo da aula. Costumamos pensar numa aula como algo retilíneo e para os expectadores esta estrutura de começo-meio-fim é muito importante, mas o palestrante deve ter sempre presente o que pretende transmitir e se ele expuser estes conceitos de várias maneiras ao longo da apresentação, aumentará a capacidade de retenção, simplesmente porque o aluno estará mais exposto àquele conceito do que se ele fosse ilustrado em apenas uma ocasião. Outro tipo de intervenção está relacionado à postura e expressão do palestrante, como por exemplo, variações do tom de voz, gesticulação, etc. Alterações das condições de iluminação da sala, interrupção para mostrar um pequeno filme ou expor uma figura, resolver um problema clínico em conjunto com a platéia, solicitar que os alunos preencham o material distribuído, etc, são todos exemplos de intervenção que podem ser utilizados na depen- 
A

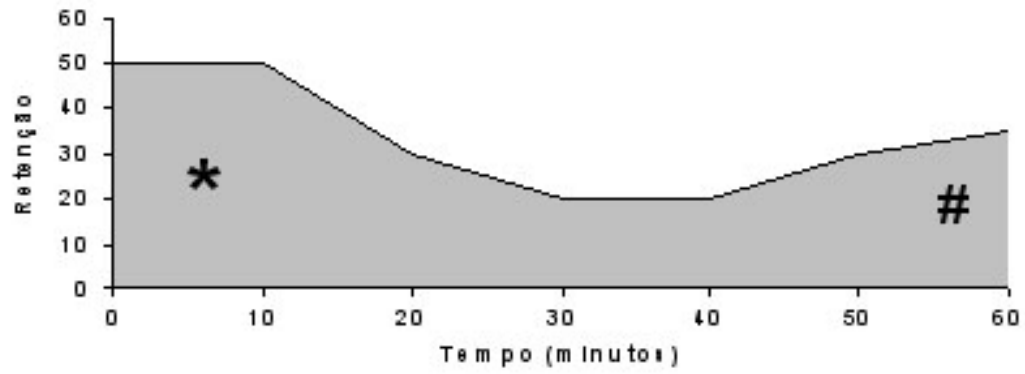

Média $=33,57 \%$

Mediana $=30 \%$

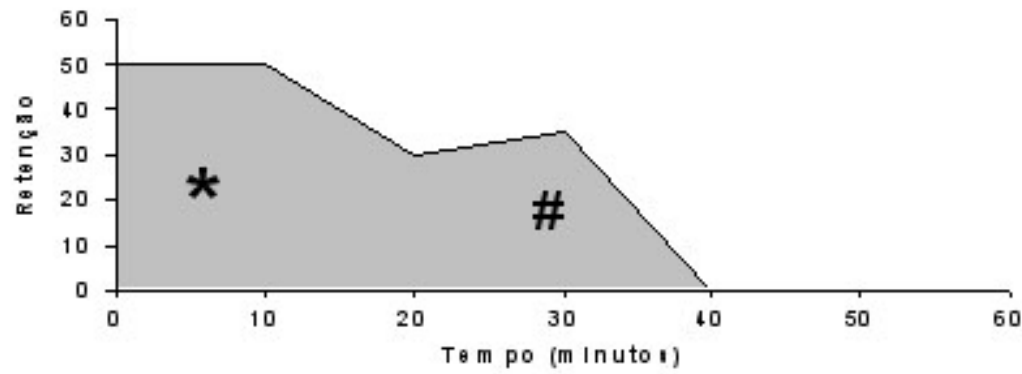

Média $=41,25 \%$

Mediana $=42,5 \%$

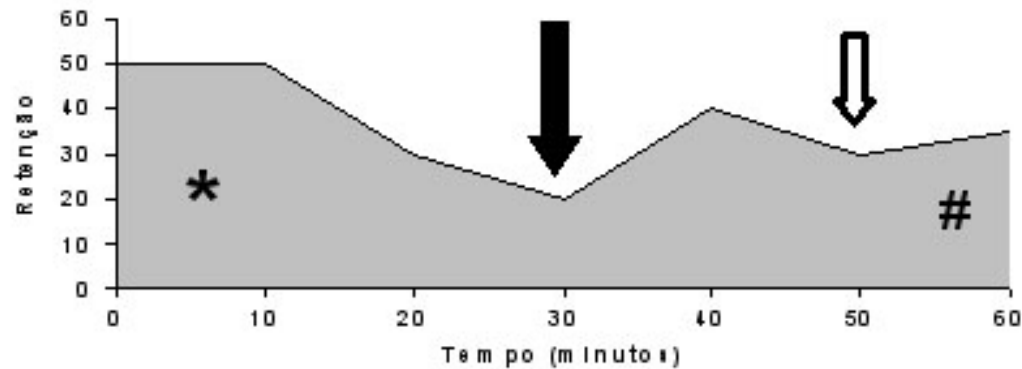

Média $=36,42 \%$

Mediana $=35 \%$

Figura 4: Influência da duração da aula e de intervenções do palestrante na retenção de informação pela platéia

A - Aula de 60 minutos de duração ilustrando que a retenção é maior em dois pontos pré-determinados da aula. Um primeiro momento é na porção inicial, assinalada com um asterisco $\left(^{*}\right)$ e o segundo ponto é na porção final, assinalada com o símbolo \#. Observe que a retenção no primeiro momento é muito maior do que no segundo. Na porção direita da figura estão ilustradas a média e mediana da retenção.

B - Exemplo do impacto da redução da atividade para 40 minutos (redução de 33\%). Observe que o porção sacrificada é justamente a porção de menor retenção e isto garante que a média e mediana sejam maiores que as de $A$.

C - Exemplo do impacto de intervenções (setas) sobre a retenção. A seta cheia ilustra uma intervenção num dos momentos de menor retenção da aula. Observe que há aumento da retenção logo após a intervenção. Uma segunda intervenção (seta não-preenchida) é realizada consecutivamente quando novamente há redução da capacidade de retenção, mas o impacto é menor do que o anteriormente observado, ressaltando a limitação das intervenções. É importante ressaltar que apesar das intervenções aumentarem a média e mediana quando comparados à situação basal $(A)$, elas ainda são inferiores às da situação $B$, em que simplesmente se limitou a duração da aula, reforçando que a objetividade e simplicidade são superiores às intervenções.

dência da criatividade do palestrante, mas sempre tendo em mente que o seu efeito diminui de acordo com o número de vezes que se utiliza.

A seleção do tipo de intervenção depende em parte das características do palestrante e, em parte, das características da platéia. Tome o exemplo de uma caricatura a ser apresentada para fazer a platéia rir. Ela pode ser bem colocada se o palestrante for desenvolto para utilizar o humor e ele conhecer o suficiente a platéia para saber que ninguém ficará ofendido com o recurso. Estas condições podem variar, o que explica porque um recurso que funcionou para uma platéia pode não funcionar com outra, embora o palestrante, o tema e os recursos audio-visuais sejam os mesmos.

Um outro ponto sobre seleção de intervenção concernente especificamente à platéia é a forma como absorvemos a informação, os chamados canais de informação. Cerca de $75 \%$ das pessoas absorvem a informação preferencialmente pela visão. Podemos depreender isto pois até os verbos de compreensão são substituídos por verbos de visão na sua fala. As- 
sim, quando querem perguntar se entendemos alguma coisa, este tipo de pessoa nos diz: "Você enxergou isto?". Outros $25 \%$ utilizam outros canais de comunicação, como a audição ("Isto não me soa bem"). Este tipo de conhecimento explica porque o melhor tipo de intervenção, sendo que o mesmo conceito se aplica parar a seleção de evidências, é baseado em recursos visuais. "Uma imagem vale mais do que mil palavras".

O resumo dos conceitos transmitidos está ilustrado na Tabela II.

\section{Tabela II - Retenção}

Fatores que influenciam a capacidade de Retenção

1. Forma como o conteúdo é transmitido - quanto maior o número de "canais" ocupados, maior será a retenção.

2. Quantidade de informação transmitida - a capacidade de retenção é inversamente relacionada à quantidade de informação.

3. Duração da exposição - a retenção diminui à medida que a atividade se prolonga

4. Retenção é variável no decorrer de uma apresentação - a retenção é maior no início da atividade e, em menor proporção, ao final da atividade. Intervenções de diversa natureza podem garantir aumentos transitórios da retenção, mas sua eficácia diminui com o aumento do número de intervenções.

\section{4- INTEGRANDO ELABORAÇÃO INTERNA E RETENÇÃO}

A Figura 5 integra os conceitos apresentados para elaboração interna e retenção da platéia. Na parte superior e central, os objetivos 1 e 2 e os tópicos/evidências a-d se referem aos exemplificados na Figura 3 e na parte inferior, os conceitos sobre retenção são os mesmos expressos na Figura 4 C. Os tópicos a-d servirão também para demarcação de quatro momentos sequenciais na aula no decorrer desta explanação.

Os objetivos 1 e 2 não são uniformemente explorados ao longo da apresentação. O objetivo 1 é detalhado ao longo de toda a apresentação, mas em menor intensidade durante o período c da aula. Já o objetivo 2 é detalhado no início, mas muito mais enfatizado nos períodos c e d da aula. Observe que estes objetivos são expostos várias vezes ao longo da aula, e por isso ilustrados em estrutura circular na Figura 5, sendo que o palestrante deve utilizar diversas formas de exposição para repetí-los exaustivamente. Ao mesmo tempo, apesar de guardarem correlação com os tópicos, os tópicos são apresentados apenas uma vez no decorrer da aula, em estrutura linear de começomeio-fim. Os tópicos são geralmente visíveis na apresentação por serem descritos nos recursos audiovisuais na maior parte das vezes.

Observar também que embora o objetivo 2 tenha sido abordado na metade final da aula, provavelmente porque necessitaremos dos conceitos que serão abordados apenas no final, está sendo tomado o cuidado de apresentá-lo após uma intervenção em c e d, garantindo maior retenção. Desta forma, estamos integrando os conceitos de elaboração com a capacidade de retenção da platéia.

\section{5- ELABORAÇÃO E DOCUMENTAÇÃO}

Por motivos didáticos, a estrutura apresentada é bem cartesiana. Na prática, o processo não é linear desta forma, mas fruto de um ciclo de tentativas, no qual, muitas vezes temos que retornar ao princípio ou ampliar nossa linha de raciocínio, incluindo ou excluindo tópicos. Além do crivo interno, quando consideramos que a aula tomou a forma próxima da desejada, é sempre importante expor este rascunho para outras pessoas, discutindo-o na sua totalidade ou algumas de suas partes críticas. Isto nos ajuda no processo de reformulação, pois alguns conceitos podem nos parecer claros quando elaboramos a aula, mas quando efetivamente tentamos transmití-los podemos perceber nossa limitação em compreendê-los ou de nos fazermos compreender. Um outro ponto importante a ser ressaltado é que muitas vezes temos a oportunidade de falar sobre o mesmo tema várias vezes e teremos a possibilidade de utilizar as vezes anteriores no processo de refinamento. Estas são oportunidades ímpares, pois nos permitem maior concentração em outros tópicos da aula além do conteúdo, facilitando, por exemplo, uma melhor compreensão da reação ("feed-back") da platéia.

A elaboração da aula pode ser facilitada por alguns recursos. Um deles é a documentação. Documentar uma aula envolve uma descrição sumária do que se pretende discutir e coletar as ilustrações e re- 


Conceito Estrutura Temporal Plano de Concretizaçẫo

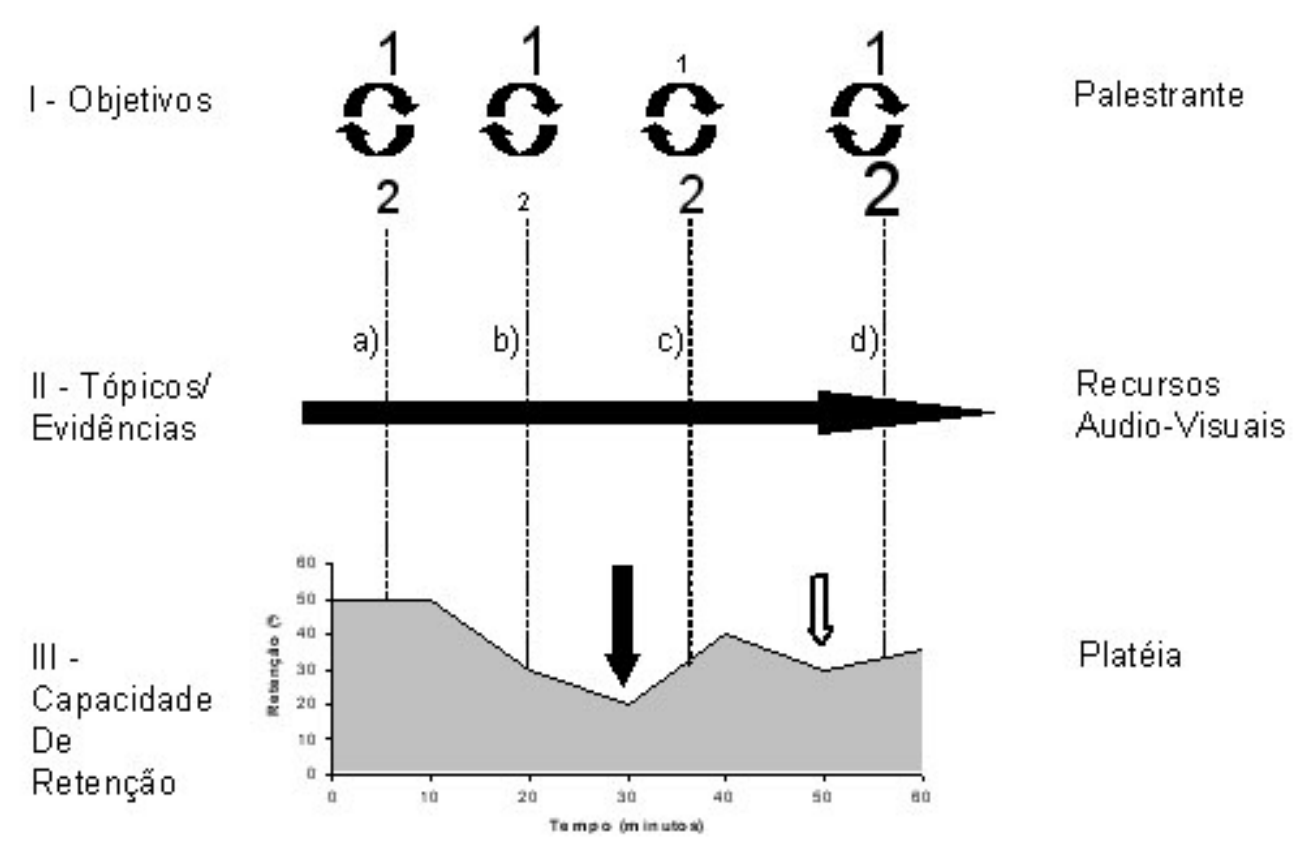

Figura 5: Associando a elaboração interna com a capacidade de retenção da platéia

A porção esquerda da figura ilustra os 3 conceitos transmitidos: Objetivos (o que se pretende transmitir), Tópicos/Evidências (o modo como será transmitido) e a Capacidade de Retenção da Platéia (o público que deverá adquirir a informação). A parte central ilustra a estrutura temporal com que a interação entre o palestrante e a platéia acontece e a porção esquerda ilustra o modo como podemos observar este tipo de integração.

Os objetivos estão delimitados na mente do palestrante e são estruturas repetitivas ao longo de toda a apresentação. Os tópicos/ evidências dão a estrutura de começo-meio-fim da apresentação e muitas vezes são refletidos nos recursos audio-visuais. $\mathrm{O}$ impacto destas duas esferas sobre a capacidade de retenção da platéia é ilustrado na porção inferior da figura. As notações da figura (números, letras e setas) são os mesmos apresentados nas Figuras 3 e 4.

cursos audio-visuais que se pretende empregar. Não está errado escrever o que se quer dizer, se este for um recurso que auxilie o palestrante a compor suas idéias. Alguns precisam concretizar o que será dito para ter a noção de que a aula está pronta. No entanto, por mais que se escreva, estará errado ler o que se escreveu na aula ou consultar suas anotações durante a apresentação, pois isto interrompe a interação com a platéia. A maioria dos programas de computador para desenvolvimento de apresentações inclue recursos que auxiliam nesta elaboração do conteúdo, facilitando a integração. Nos capítulos sobre Forma e Recursos Audio-visuais estes tópicos serão mais detalhados. Um erro comum sobre documentação é exatamente não documentar a aula. Documentação é importante por nos forçar a pensar sobre o assunto e concretizar nossos objetivos. Quando assumimos que a aula é apenas um apanhado de diapositivos e que a experiência vai fazer o resto, estamos fadados ao fracasso. Um últi- mo ponto sobre documentação é que ela é importante também quando a aula termina. Manter um "diário" de suas atividades didáticas pode ser uma excelente fonte de recursos para apresentações posteriores. $\mathrm{O}$ mesmo se aplica a apresentações de outros palestrantes. Como exposto, jamais poderemos reproduzir a aula de outro palestrante na sua totalidade, mas podemos aprender técnicas e situações em que elas foram bem aplicadas.

Para finalizar, cabe o comentário que tudo o que foi exposto até o momento é um plano desenvolvido na fase anterior à aula. Embora seja sempre interessante ter a atividade programada, devemos estar preparados para situações imprevistas quando nos depararmos com a atividade presencial da aula, que nos forçarão a adaptarmos em tempo real para o que vamos encontrar. Estes recursos de adaptação serão expostos no capítulo sobre interação com a platéia. 
Pazin Filho A, Scarpelini S. Structure of a lecture I: content. Medicina (Ribeirão Preto) 2007; 40 (1): 17-27.

ABSTRACT: The information to be transmitted in a lecture is developed based on the speaker's internal elaboration of the knowledge and the listener's capacity to retain the amount of information. The first step is defining the objectives, the message that is expected to be retained in the end of the presentation. Based on these objectives, the speaker will select topics, small amount of information essential to the general message be comprehended, and evidences to illustrate them. These topics/evidences should have a beginning-middle-end structure. It is fundamental to take into consideration the listener's capacity of retention, which is influenced by the way the information is transmitted, the amount of information transmitted, the duration of the lecture and by the interventions the speaker can make. All these characteristics guarantee that the amount of information should be carefully selected, giving just enough information to keep retention.

Keywords: Lecture; contents; elaboration; retention. Education, Medical.

\section{REFERÊNCIAS CONSULTADAS}

1 - Alley M. The craft of scientific presentations: critical steps to succeed and critical errors to avoid. Blacksburg,VA: Springer; 2003.

2 - Galbraith MW. Adult learning methods: a guide for effective instruction. 1st ed. Malabar, FL: Robert E. Krieger Publishing; 1990.

3 - Instructor's manual for advanced cardiac life support. 2nd ed. Dallas, Tex: American Heart Association; 1988.

4 - Pazin Filho A, Scarpelini S, Schmidt A. Análise qualitativa da elaboração e apresentação de aulas teóricas por alunos de pós-graduação da Faculdade de Medicina de Ribeirão Preto Universidade de São Paulo. Medicina (Ribeirão Preto) 2007; 40 (1): 51-62.
5 - Priest G. Logic: a very short introduction. 1st ed. Oxford (UK): Oxford University Press; 2000.

6 - Rogers A. Teaching adults. 3rd ed. Philadelphia, PA: Open University Press; 2002.

7 - Sillars MO, Rieke RD. Argumentation and critical decision making. 4th ed. Boston(MS): Allyn and Bacon; 1996.

8 - Zarefsky D. Public speaking: strategies for success. 3rd ed. Boston (MS): Allyn and Bacon; 2002.

Recebido em 07/11/2006

Aprovado em 13/03/2007 